\title{
Genetic architecture of recent-onset dilated cardiomyopathy in Moravian region assessed by whole-exome sequencing and its clinical correlates
}

\author{
Anna Chaloupkaa , Lenka Piherova ${ }^{b}$, Ilga Grochovaa , Jana Binovac, Jan Krejcia, Lenka Spinarovaa , Viktor Stranecky ${ }^{b}$, \\ Stanislav Kmoch ${ }^{b}$, Milos Kubanekc
}

\begin{abstract}
Aims. Recent-onset dilated cardiomyopathy (RODCM) is a disease of heterogeneous aetiology and clinical outcome. In this pilot study, we aimed to assess its genetic architecture and correlate genotype with left ventricular reverse remodelling (LVRR).

Patients and Methods. In this multi-centre prospective observational study, we enrolled 83 Moravian patients with RODCM and a history of symptoms of less than 6 months, for whole-exome sequencing (WES). All patients underwent 12-month clinical and echocardiographic follow-up. LVRR was defined as an absolute increase in left ventricular ejection fraction $>10 \%$ accompanied by a relative decrease of left ventricular end-diastolic diameter $>10 \%$ at 12 months. Results. WES identified at least one disease-related variant in 45 patients (54\%). LVRR occurred in 28 patients (34\%), most often in carriers of isolated titin truncated variants, followed by individuals with a negative, or inconclusive WES and carriers of other disease-related variants ( $56 \%$ vs. $42 \%$ vs. $19 \%, P=0.041$ ).

Conclusion. A substantial proportion of RODCM cases have a monogenic or oligogenic genetic background. Carriers of non-titin disease-related variants are less likely to reach LVRR at 12-months than other individuals. Genetic testing could contribute to better prognosis prediction and individualized treatment of RODCM.
\end{abstract}

Key words: dilated cardiomyopathy, familial cardiomyopathy, next generation sequencing, genetic architecture, cardiac remodelling

Received: July 31, 2018; Accepted: September 7, 2018; Available online: September 24, 2018

https://doi.org/10.5507/bp.2018.054

(c) 2019 The Authors. This is an open access article licensed under the Creative Commons Attribution License

(https://creativecommons.org/licenses/by/4.0/).

${ }^{a} 7^{\text {st }}$ Internal Clinic of Cardio-angiology, St. Anne's University Hospital and Faculty of Medicine, Masaryk University, Brno, Czech Republic ${ }^{b}$ Research Unit for Rare Diseases, Department of Paediatrics and Adolescent Medicine, $1^{\text {st }}$ Faculty of Medicine, Charles University, Prague, Czech Republic

'Department of Cardiology, Institute for Clinical and Experimental Medicine, Prague, Czech Republic.

Corresponding author: Anna Chaloupka, e-mail:anna.chaloupka@fnusa.cz

\section{INTRODUCTION}

Dilated cardiomyopathy (DCM) is a prevalent disease leading to chronic heart failure $(\mathrm{CHF})$. It has a heterogeneous aetiology including genetic, inflammatory, toxic and metabolic causes ${ }^{1,2}$. The clinical diagnosis of DCM is based on the presence of left ventricular (LV) systolic dysfunction in the absence of abnormal loading conditions or significant coronary artery disease sufficient to cause global systolic impairment ${ }^{2,3}$. In routine practice, the aetiology of DCM remains often unexplained due to incomplete assessment of family history or recognition of clinical red-flags, suggesting genetic etiology ${ }^{4}$. In addition, potentially reversible causes of DCM like myocarditis and toxic injury may be undiagnosed due to insufficient accuracy of non-invasive diagnostic tools to confirm myocarditis, or concealed history of alcohol, or drug abuse $e^{5,6}$.

An ultimate diagnostic and prognostic challenge are patients with recent-onset DCM (RODCM) who may have variable clinical outcomes ranging from complete recovery of LV systolic dysfunction to rapid progression to end-stage CHF or sudden cardiac death ${ }^{7}$. Importantly, left ventricular reverse remodelling (LVRR), defined as a par- tial improvement of LV systolic function accompanied by reduction of LV volumes, has been identified as a marker of favourable prognosis in RODCM (ref..$^{8-10}$ ). LVRR may indicate either the beneficial effect of pharmacotherapy, disappearance of myocardial toxic or inflammatory insult. Due to the permanent character of myocardial damage, LVRR should be less prevalent in genetic forms of DCM (ref. ${ }^{7,11}$ ).

Tremendous advances have been made in understanding the genetic basis of DCM over the last 30 years. To date, hundreds of mutations in more than 40 genes encoding proteins with various cellular functions have been identified as causing DCM (ref. ${ }^{12-14}$ ). The predominating molecular cause seem to be truncating titin variants, responsible for almost a quarter cases of familial DCM $\left(\right.$ ref. ${ }^{14}$ ). Most familial forms of DCM are monogenic disorders, most commonly with autosomal dominant inheritance $^{15,16}$. Some genotypes like mutations of $L M N A$, $P L N$, and $R B M 20$ have been associated with severe forms of CHF and / or malignant ventricular arrhythmias ${ }^{17-19}$. Cardiomyopathy gene panels are usually used in clinical settings to screen the most common disease-causing genes. Discovery of next-generation sequencing (NGS) en- 
ables us to screen whole protein-coding genome (exome) in a timely and cost-effective way and thus substantially increase mutation detection in both sporadic and familial cases of DCM $\left(\right.$ ref. $\left.^{20}\right)$. Recognition of the genetic component, particularly in patients with RODCM or their asymptomatic relatives, could improve risk stratification and thus diagnostic and therapeutic management.

The above formed the motivation for deciding to assess the genetic architecture of RODCM with wholeexome sequencing (WES), and to study the genotypephenotype correlates. Specifically, we wanted to analyse the relationship between the results of WES and left ventricular reverse remodelling. The analysis was designed as a pilot study of the first WES results derived from a large project of WES in RODCM.

\section{MATERIALS AND METHODS}

\section{Patients and study design}

Patients were recruited in the Department of $1^{\text {st }}$ Internal Cardio-angiology, St. Anne's University Hospital in Brno, Czech Republic. This multi-centre prospective observational study was approved by the Institutional Ethics Committee at all respective participating institutions and all patients signed the written informed consent.

Table 1. Patient characteristics.

\begin{tabular}{|c|c|c|}
\hline Variable & $\begin{array}{c}\text { Baseline } \\
(\mathrm{n}=83)\end{array}$ & $\begin{array}{l}\text { 12-month follow-up } \\
(\mathrm{n}=83)\end{array}$ \\
\hline Age [years] & $48(40-56)$ & - \\
\hline \multirow[t]{2}{*}{ Gender (males/females) } & $68(82 \%)$ & - \\
\hline & $15(18 \%)$ & \\
\hline Arterial hypertension & $33(40 \%)$ & - \\
\hline Diabetes mellitus & $10(12 \%)$ & - \\
\hline Positive family history of DCM & $14(17 \%)$ & - \\
\hline \multirow[t]{4}{*}{ NYHA class } & I - $3(4 \%)$ & $I-22(26 \%)$ \\
\hline & II $-40(48 \%)$ & II - $44(53 \%)$ \\
\hline & III - $39(47 \%)$ & III - $17(21 \%)$ \\
\hline & IV - $1(1 \%)$ & IV - $0(0 \%)$ \\
\hline Systolic BP [mmHg] & $120(115-130)$ & $128(115-145)$ \\
\hline Diastolic BP [mmHg] & $80(75-87)$ & $87(80-95)$ \\
\hline Heart rate $[\mathrm{bpm}]$ & $80(69-90)$ & $70(60-80)$ \\
\hline Sinus rhythm & $82(99 \%)$ & $80(96 \%)$ \\
\hline QRS duration [ms] & $100(80-120)$ & $108(100-129)$ \\
\hline LVEDD [mm] & $65(60-70)$ & $61(55-67)$ \\
\hline LVEDV [mL] & $214(179-260)$ & $187(153-237)$ \\
\hline LVEF [\%] & $25(17-30)$ & $35(27-45)$ \\
\hline $\mathrm{E} / \mathrm{Em}$ & $13(10-19)$ & $9(7-11)$ \\
\hline Left atrium (PLAX) [mm] & $45(42-49)$ & $42(37-46)$ \\
\hline RVEDD (PLAX) [mm] & $34(30-38)$ & $32(28-35)$ \\
\hline TAPSE [mm] & $18(16-21)$ & $21(18-24)$ \\
\hline $\mathrm{RV} \mathrm{Sm}[\mathrm{cm} / \mathrm{s}]$ & $10(9-12)$ & $13(11-15)$ \\
\hline $\mathrm{ACEi}$ & $63(76 \%)$ & $73(88 \%)$ \\
\hline ARB & $6(7 \%)$ & $10(12 \%)$ \\
\hline Equivalent dose of ACEi or ARB $\geq 50 \%$ & $25(30 \%)$ & $39(47 \%)$ \\
\hline Beta-blockers & $74(89 \%)$ & $83(100 \%)$ \\
\hline Equivalent dose of betablockers $\geq 50 \%$ & $14(17 \%)$ & $27(32 \%)$ \\
\hline Aldosterone receptor blockers & $58(70 \%)$ & $66(79 \%)$ \\
\hline Furosemide & $62(75 \%)$ & $70(84 \%)$ \\
\hline Furosemide $\geq 40$ mg daily & $45(54 \%)$ & $46(55 \%)$ \\
\hline Sodium [mmol/L] & $140(138-142)$ & $141(139-142)(n=68)$ \\
\hline Creatinine $[\mu \mathrm{mol} / \mathrm{L}]$ & $86(76-98)$ & $81(75-91)(n=70)$ \\
\hline NT-proBNP [ng/mL] & $1664(751-3232)$ & $446(109-779)(n=69)$ \\
\hline
\end{tabular}

Patient characteristics at baseline and 12-month follow-up. Continuous variables are shown as median and IQR, discrete variables as absolute and relative frequency.

DCM - dilated cardiomyopathy, NYHA class - New York Heart Association class, BP - blood pressure, LVEDD - left ventricular end-diastolic diameter, LVEDV - left ventricular end-diastolic volume, LVEF - left ventricular ejection fraction, PLAX - parasternal long axis, RVEDD - right ventricular end-diastolic diameter, TAPSE - tricuspid annular plane systolic excursion, RV Sm - right ventricular Sm wave, ACEi - angiotensin converting enzyme inhibitor, ARB - angiotensin receptor blocker. 
All clinical, genomic data and samples were independently anonymized and stored in secured local databases according to the provisions of the Czech data protection authority (www.uoou.cz) and in accordance with Act 373/2011 Sb (\$28-29). We prospectively enrolled 83 consecutive patients with recent-onset DCM, specified by a history of heart failure of less than 6 months. DCM was defined in accordance with the ESC definition by the presence of LV dilatation (LVEDD $33 \mathrm{~mm} / \mathrm{m}$ in men and $32 \mathrm{~mm} / \mathrm{m}$ in women) and LV systolic dysfunction (LVEF $<45 \%$ ) in the absence of abnormal loading conditions (hypertension, valve disease) or coronary artery disease sufficient to cause global systolic impairment ${ }^{2}$. Other inclusion criteria were age $\geq 18$ years and signed informed consent. DCM was considered familial when at least 2 genetically related first-degree relatives were diagnosed with DCM, or in cases of premature sudden cardiac death or CHF in a first-degree relative. Exclusion criteria, except for the already mentioned hypertension, valvular disease and coronary artery disease encompassed proven myocarditis or specific antibiotic, antiviral or immunosuppressive therapy, post-tachycardic, toxic, metabolic or endocrine aetiology, and specific therapy affecting natural ventricular remodelling such as resynchronization therapy and ventricular assist devices.

Initial patient assessment included 3-generation family history, physical examination, ECG, echocardiographic examination, routine blood tests, and collection of $5 \mathrm{~mL}$ of noncoagulated peripheral venous blood for molecular genetic testing. All patients received standard heart failure pharmacotherapy. Equivalent doses of angiotensin converting enzyme inhibitors, angiotensin receptor blockers and beta-blockers were expressed as a percentage of the maximum recommended daily dose according to the latest ESC guidelines ${ }^{1}$. All patients were followed-up by clinical examination, ECG, echocardiography and routine blood tests at 12 months, to assess cardiac remodelling. Echocardiography was performed by experienced operators in accordance with the guidelines of the American Society of echocardiography ${ }^{21,22}$ - M-mode, 2D images and Doppler recordings were obtained using a Vivid E9 (GE Healthcare, Chalfont St Giles, UK). The LVEF was assessed using Simpson's biplane method.

Patients with a positive genetic screening were invited for genetic counselling by a clinical geneticist and their first-degree relatives were invited for clinical cardiology assessment - ECG, echocardiography, and after signing an informed consent, a gene-specific genetic testing, in line with current recommendations ${ }^{23}$. Table 1 describes the study group characteristics.

\section{Next-generation sequencing (NGS)}

Genomic DNA was extracted from peripheral blood samples (EDTA blood) using a standard Qiagen SPE extraction kits. Exome sequencing was performed using 1 $\mu \mathrm{g}$ of DNA from affected individuals. For DNA enrichment of barcoded DNA libraries were used SeqCap EZ MedExome Target Enrichment Kit (Roche, Madison, USA) according to the manufacturer's protocol. DNA sequencing was performed on the captured barcoded DNA library using the Illumina Hiseq 2500 system at the Genomic facility in Motol University Hospital in Prague. The resulting FASTQ files were aligned to the Human Genome Reference (hg19) using Novoalign (3.02.10). Following genome alignment, conversion of SAM format to BAM and duplicate removal were performed using Picard Tools (1.129). The Genome Analysis Toolkit, GATK (3.3) (ref. ${ }^{24}$ ) was used for local realignment around indels, base recalibration and variant recalibration and genotyping.

\section{Variant annotation and classification}

Variant annotation was performed with SnpEff (ref. ${ }^{25}$ ) and GEMINI $\left(\right.$ ref. $^{26}$ ). Only the sequence having a frequency lower than 0.0005 in the dbSNP, ExAC (http://exac. broadinstitute.org/), gnomAD (http://gnomad.broadinstitute.org/) and our internal exome database were prioritized for further analysis. Identified genetic variants were filtered according to the expected autosomal dominant model of the disease and evaluated according to the biological relevance of the corresponding genes. Candidate variants were visualized in Integrative Genomics Viewer (IGV) - version 2.3.32 (ref. ${ }^{27}$ ).

Standard variant classification ${ }^{28}$ was adopted according to the guidelines for the interpretation of sequence variants ${ }^{29}$ dividing variants into 5 groups as 1 . Benign, 2. Likely benign, 3. Variants of uncertain significance, 4. Likely pathogenic and 5. Pathogenic. Mutation Taster tool (www.mutationtaster.org) (ref. ${ }^{30}$ ) was used to evaluate the disease-causing potential of the sequence variants and only variants in group 5. pathogenic, 4. likely pathogenic, and selected 3. variants of unknown significance where Mutation Taster predicted pathogenic variant were considered to be disease-related, the remaining variants were classified as non-significant.

\section{Cardiology assessment and gene-specific testing in first-degree relatives}

All patients with positive genetic results were invited by letter for genetic counselling by a clinical geneticist and their first-degree relatives were invited for clinical cardiology assessment - ECG, echocardiography, and after signing an informed consent, a gene-specific genetic testing using Sanger sequencing method to study segregation in families.

\section{Statistical analysis}

Categorical data were expressed as percentages and compared using the chi-squared test and Fisher's exact test. Continuous variables were expressed as means (SD) or medians and interquartile range. They were compared using the Student t-test for paired or unpaired data, and by the non-parametric Mann-Whitney test, or Wilcoxon test where appropriate. For all tests, a probability value of $P<0.05$ was considered significant. The data were analysed using statistical software SPSS (Chicago, Illinois, USA) for Windows, version 17.0. 


\section{Genotype-phenotype association analysis}

Patients with RODCM were characterized by age, gender, family history of DCM, concomitant diseases, NYHA class, blood pressure and ECG characteristics, pharmacotherapy, laboratory results, and echocardiography parameters at baseline and at 12-month follow-up.
Whole-exome sequencing was carried out for all subjects. LVRR was defined as an absolute increase in left ventricular ejection fraction (LVEF) > 10\% accompanied by a relative decrease of left ventricular end-diastolic diameter (LVEDD) $>10 \%$ at 12-month follow-up. Association with genetic causes and specific gene mutations was examined.
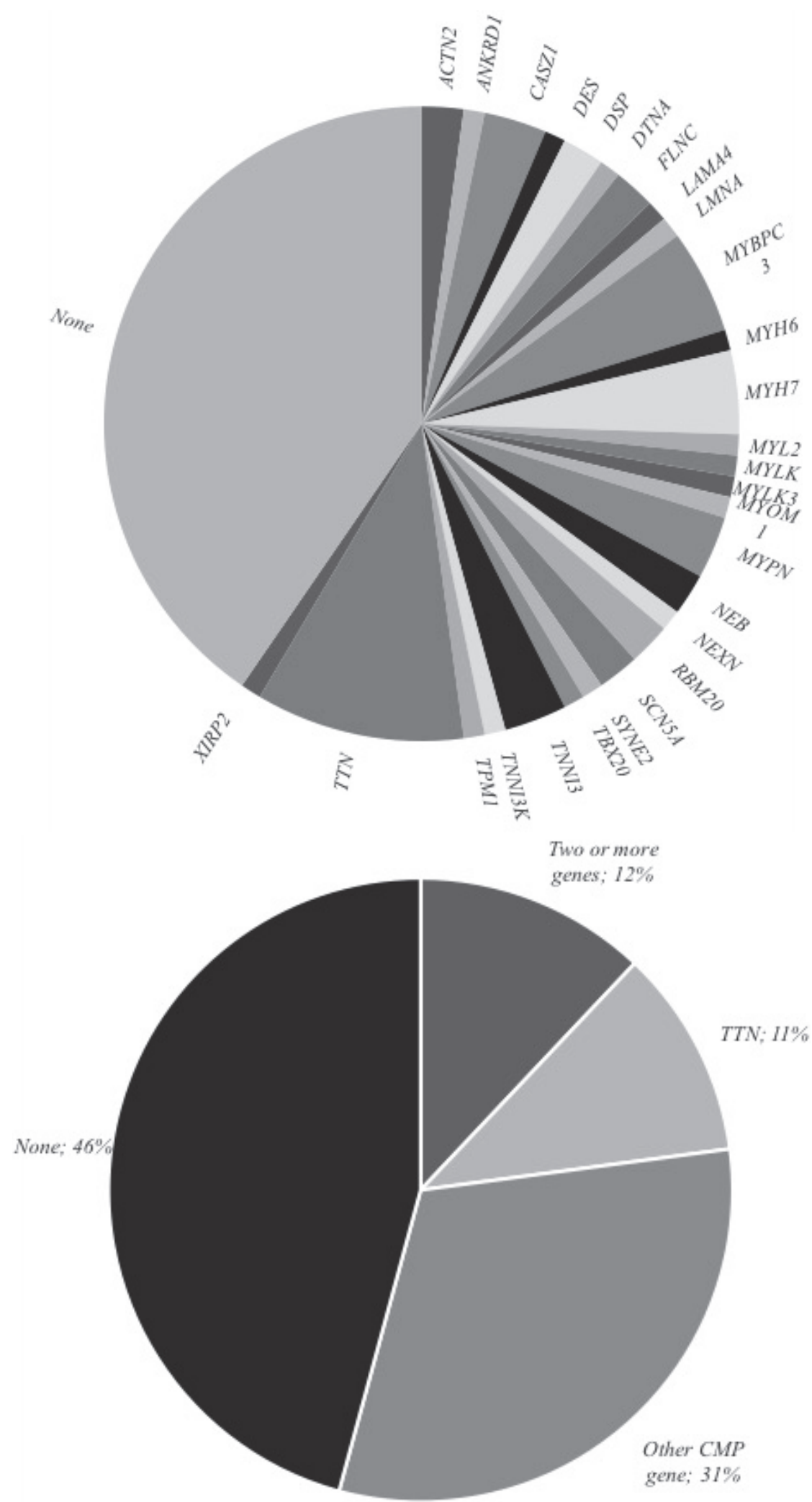

\section{Panel A}

Panel A shows gene variant distribution. Only genes with disease-related variants shown, the variants classified as non-conclusive, or where no variants were found are labelled as "None". Abbreviations: ACTN2 - alpha-actinin 2, $A N K R D 1$ - ankyrin repeat domain 1, CASZ1 castor zinc finger 1, DES - desmin, $D S P$ - desmoplakin, DTNA - dystrobrevin alpha, FLNC - filamin C, LAMA4 - laminin subunit alpha 4, $L M N A$ - lamin A/C, MYBPC3 - myosin binding protein $\mathrm{C}, M Y H 6$ - myosin heavy chain 6 , MYH7 - myosin heavy chain 7, MYL2 - myosin light chain 2, MYLK - myosin light chain ligase, MYLK3 - myosin light chain kinase 3, MYOM1 - myomesin 1, MYPN - myopalladin, $N E B$ - nebulin, $N E X N$ - nexilin, $R B M 20$ - RNA-binding protein $20, S C N 5 A$ - type V voltage-gated cardiac Na channel, SYNE2 nesprin, TBX20 - T-box 20, TNNI3 - Cardiac troponin I3, TNNI3K - Cardiac troponin I3 interacting kinase, TPM1- alpha-tropomyosin, $T T N$ - titin, XIRP2 - Xin Actin Binding Repeat Containing 2

Panel B

Panel B illustrates the percentage of RODCM patients divided into 4 categories according to identified variants - none/non-conclusive "None", only titin (TTN) variant "TTN", only other cardiomyopathy-related gene variant "Other CMP gene", and $\geq 2$ identified diseaserelated gene variants "Two or more genes". Eight patients had variants in 2 genes (MYPN + MYOM1, MYPN + MYH6, TNNI3 + LAMA4, TNNI3 + MYL2, CASZ1 + TTN, CASZ1 + SCN5A, RBM20 + ACTN2 and DES + LMNA). In one patient we identified 2 rare variants in $N E B$ gene and 1 variant in DTNA gene.

Abbreviations: TTN - titin, CMP - cardiomyopathy, ACTN2 - alpha-actinin 2, 1, CASZ1 - castor zinc finger 1, DES - desmin, DTNA dystrobrevin alpha, LAMA4 - laminin subunit alpha 4, LMNA - lamin A/C, MYH6 - myosin heavy chain 6, MYL2 - myosin light chain 2 , MYOM1 - myomesin 1, MYPN - myopalladin, $N E B$ - nebulin, RBM20 - RNA-binding protein 20, SCN5A - type V voltage-gated cardiac $\mathrm{Na}$ channel, TNNI3 - Cardiac troponin I3, TTN - titin

Fig. 1. A, B. Gene distribution in RODCM. 
Table 2. Left ventricular reverse remodelling and results of WES.

\begin{tabular}{|c|c|c|c|c|}
\hline & $\begin{array}{l}\text { Exom negative } \\
\text { or non-conclusive } \\
(\mathrm{n}=38)\end{array}$ & $\begin{array}{l}\text { Isolated titin } \\
\text { truncating mutation } \\
\qquad(\mathrm{n}=9)\end{array}$ & $\begin{array}{l}\text { Other variant } \\
\text { or combination } \\
\quad(n=36)\end{array}$ & $P$ \\
\hline $\begin{array}{l}12 \text { months } \Delta \text { LVEF absolute } \\
\text { (percent points) }\end{array}$ & $16(6-23)$ & $15(9-34)$ & $6(3-15)$ & 0.036 * \\
\hline $\begin{array}{l}12 \text { months } \\
\Delta \text { LVEDD relative }(\%)\end{array}$ & $-7.7(-13.4$ to 3.7$)$ & $-11.3(-18.9$ to -7.1$)$ & $-1.5(-12$ to 1.7$)$ & 0.086 \\
\hline $\begin{array}{l}12 \text { months } \\
\Delta \text { LVEF }>10 \text { points }(n=44 ; 53 \%)\end{array}$ & $24(63 \%)$ & $7(78 \%)$ & $13(36 \%)$ & $0.019 *$ \\
\hline $\begin{array}{l}12 \text { months } \\
\Delta \text { LVEDD }<-10 \%(n=34 ; 41 \%)\end{array}$ & $18(47 \%)$ & $6(67 \%)$ & $10(28 \%)$ & 0.058 \\
\hline $\begin{array}{l}12 \text { months } \\
\Delta \text { LVEF }>10 \text { points and } \Delta \text { LVEDD }<-10 \% \\
(n=28 ; 34 \%)\end{array}$ & $16(42 \%)$ & $5(56 \%)$ & $7(19 \%)$ & $0.041 *$ \\
\hline
\end{tabular}

Relationship between results of whole-exome sequencing and LVRR

$\mathrm{n}$ - number, $\triangle$ LVEF absolute - absolute change of left ventricular ejection fraction, $\Delta$ LVEDD relative - relative change of left ventricular enddiastolic diameter

\section{RESULTS}

\section{Clinical and genetic screening for familial DCM}

In our well-defined cohort of 83 consecutive patients with RODCM (for patient characteristics see Table 1) we found a positive family history of DCM in 14 patients (17\%), while 69 patients (83\%) appeared to be sporadic cases. WES suggested much stronger genetic determination of RODCM than the family history itself. NGS genetic testing uncovered disease-causing pathogenic variants in 45 patients ( $54 \%$ ) and only 38 patients (46\%) had non-conclusive, or negative genetic result.

\section{Whole-exome sequencing data (WES)}

As expected, the gene spectrum of identified variants in RODCM was quite wide (Fig. 1) comprising a total of 28 different genes, with the majority of truncating variants in titin $(T T N)$ gene which was found in $10(12 \%)$ patients. Other known cardiomyopathy genes were identified in 26 (31\%) of all patients, with most variants in sarcomeric genes - cardiac myosin binding-protein C (MYBPC3), beta-myosin heavy chain 7 (MYH7), cardiac troponin I3 (TNNI3). Other rare variants included genes coding proteins in various myocyte compartments - sarcomere (MYH6, TPM1, TNNI3K, MYL2, MYL3, MYLK, MYOM1), Z-disc ( $A C T N 2, M Y P N, N E X N, N E B, A N K R D 1)$, cytoskeleton ( $D E S, F L N C)$, desmosomes $(D S P)$, nuclear envelope (LMNA, SYNE2), nucleus (RBM20, CASZ1, TBX20), ion channels ( $S C N 5 A)$, dystrophin complex (DTNA), and extracellular matrix (LAMA4). Some of the pathogenic gene variants affected genes which were not previously described as typical DCM genes but were annotated to other cardiomyopathies or affect heart development. A large number of studies suggest the additive effect of several mutations in different genes in a single patient, sometimes dubbed as oligogenic inheritance ${ }^{28}$. In our cohort, 10 patients $(12 \%)$ had pathogenic variants in $\geq 2$ genes.

Fig. 1. A and B pie chart shows gene distribution in RODCM.

\section{Cardiology assessment and gene-specific testing in first-degree relatives}

The clinical and genetic cascade screening in families is still ongoing. To date, the family response rate is 23 (48\%) for genetic testing and 18 (37.5\%) for cardiology assessment. In total, we already assessed 47 first-degree relatives genetically and 35 clinically, the mean was 2 firstdegree relatives per patient. Sanger sequencing uncovered 13 (48.1\%) family members with positive segregation of the disease-causing variant, all of them were asymptomatic and none of them met the DCM echocardiographic criteria, even though we were able to detect mild changes as grade I diastolic dysfunction and non-specific ECG abnormalities (early repolarization, negative $\mathrm{T}$ waves). Cardiology assessment uncovered only 1 patient $(2.9 \%)$ with DCM who was previously diagnosed and treated, and the gene-specific testing results of this patient are not available yet). In addition, 16 (45.7\%) of asymptomatic first-degree relatives showed mild echocardiographic and ECG abnormalities which may precede the development of the disease.

\section{Development of clinical and echocardiographic characteristics at $\mathbf{1 2}$ months}

We observed a significant improvement in several important clinical characteristics at 12 months of follow-up. Both subjective (NYHA class $P<0.001$ ) and objective (NT-proBNP level, $P<0.001)$ markers of heart failure improved significantly in the whole cohort (Table 1). Left ventricular echocardiographic parameters also showed significant improvement (LVEF, $P<0.001)$ and LVEDD, $P<0.001$ ) (Table 1).

\section{Genetic prediction of reverse remodelling}

We found a moderate association between the development of left ventricular echocardiographic parameters at 12 months and WES results in our recent-onset DCM patient cohort. Individuals with a negative or non-conclusive WES result had a higher occurrence of LVRR and more favourable changes of LVEF and LVEDD than 
Table 3. Left ventricular reverse remodelling and baseline patient characteristics.

\begin{tabular}{|c|c|c|c|}
\hline \multirow[t]{2}{*}{ Variable } & \multicolumn{2}{|c|}{ Prediction of 12 months $\Delta$ LVEF $>10$ points and $\Delta$ LVEDD $<-10 \%$} & \multirow[t]{2}{*}{$P$-value } \\
\hline & $\begin{array}{l}\text { Positive pts } \\
(\mathrm{n}=28 \mathrm{pts})\end{array}$ & $\begin{array}{l}\text { Negative pts } \\
(\mathrm{n}=55 \mathrm{pts})\end{array}$ & \\
\hline Age [years] & $46(38-54)$ & $49(44-57)$ & 0.200 \\
\hline Gender & $18(64 \%)$ & $50(91 \%)$ & \\
\hline (males / females) & $18(64 \%) / 10(36 \%)$ & $50(91 \%) / 5(9 \%)$ & $0.003 * *$ \\
\hline Arterial hypertension & $15(53 \%)$ & $18(33 \%)$ & 0.067 \\
\hline Diabetes & $2(7 \%)$ & $8(14 \%)$ & 0.126 \\
\hline Positive family history of DCM & $3(11 \%)$ & $11(20 \%)$ & 0.285 \\
\hline \multirow[t]{4}{*}{ NYHA class } & I - $1(4 \%)$ & $\mathrm{I}-2(4 \%)$ & 0.116 \\
\hline & II $-9(32 \%)$ & II $-31(56 \%)$ & \\
\hline & III - $17(44 \%)$ & III - $22(40 \%)$ & \\
\hline & IV - $1(4 \%)$ & IV - $0(0 \%)$ & \\
\hline Systolic BP [mmHg] & $120(110-132)$ & $124(116-130)$ & 0.477 \\
\hline Diastolic BP [mmHg] & $80(75-85)$ & $80(75-87)$ & 0.659 \\
\hline Heart rate $[\mathrm{bpm}]$ & $83(70-100)$ & $80(69-88)$ & 0.156 \\
\hline QRS [ms] & $90(80-100)$ & $100(80-132)$ & 0.225 \\
\hline LBBB & $6(21 \%)$ & $16(29 \%)$ & 0.318 \\
\hline LVEDD [mm] & $63(59-71)$ & $65(60-70)$ & 0.370 \\
\hline LVEF [\%] & $23(16-25)$ & $25(17-30)$ & 0.339 \\
\hline $\mathrm{E} / \mathrm{Em}$ & $13(8-17)$ & $13(10-19)$ & 0.878 \\
\hline Left atrium (PLAX) [mm] & $45(40-49)$ & $45(42-49)$ & 0.518 \\
\hline RVEDD [mm] & $33(28-38)$ & $35(31-39)$ & 0.347 \\
\hline TAPSE [mm] & $18(17-20)$ & $18(15-23)$ & 0.774 \\
\hline $\mathrm{RV} \mathrm{Sm}[\mathrm{cm} / \mathrm{s}]$ & $10(8-11)$ & $11(9-12)$ & 0.092 \\
\hline $\mathrm{ACEi}$ & $22(78 \%)$ & $41(65 \%)$ & 0.685 \\
\hline $\mathrm{ARB}$ & $5(18 \%)$ & $1(2 \%)$ & 0.348 \\
\hline Equivalent dose of ACEi or ARB $\geq 50 \%$ & $8(28 \%)$ & $17(31 \%)$ & 0.444 \\
\hline Beta-blockers & $25(89 \%)$ & $49(66 \%)$ & 0.978 \\
\hline Equivalent dose of betablockers $\geq 50 \%$ & $6(21 \%)$ & $8(14 \%)$ & 0.309 \\
\hline Aldosterone receptor blockers & $19(71 \%)$ & $39(68 \%)$ & 0.482 \\
\hline Furosemide $\geq 40 \mathrm{mg}$ daily & $12(43 \%)$ & $33(60 \%)$ & 0.106 \\
\hline Sodium [mmol/L] & $140(138-142)$ & $140(138-143)$ & 0.375 \\
\hline Creatinine $[\mu \mathrm{mol} / \mathrm{L}]$ & $78(63-91)$ & $88(78-100)$ & $0.018 *$ \\
\hline NT-proBNP [ng/mL] & $2053(1087-3741)$ & $1298(745-2801)$ & 0.134 \\
\hline
\end{tabular}

Association between baseline patient variables and LVRR ( $\triangle \mathrm{LVEF}>10 \%$ and $\triangle \mathrm{LVEDD}<-10 \%)$

$\mathrm{n}$ - number, pts - patients, $\triangle \mathrm{LVEF}$ - change of left ventricular ejection fraction, $\Delta$ LVEDD - change of left ventricular end-diastolic diameter, DCM - dilated cardiomyopathy, NYHA class - New York Heart Association class, BP - blood pressure, LBBB - left bundle branch block, LVEDD - left ventricular end-diastolic diameter, LVEDV - left ventricular end-diastolic volume, LVEF - left ventricular ejection fraction, PLAX - parasternal long axis, RVEDD - right ventricular end-diastolic diameter, TAPSE - tricuspid annular plane systolic excursion, RV Sm - right ventricular Sm wave, ACEi - angiotensin converting enzyme inhibitor, ARB - angiotensin receptor blocker

patients with non-titin disease-related variants (Table 2). Interestingly, 9 carriers of isolated titin truncating variants achieved similar or even better improvement in LVEF and LVEDD (LVRR prevalence in 56\% of cases) compared to individuals with negative or non-conclusive WES. (Table 2). Table 3 describes the other baseline variables and their relationship to 12-month LVRR. Interestingly, female gender and a lower baseline creatinine serum levels predicted LVRR.

\section{DISCUSSION}

To the best of our knowledge, our project is the first study correlating prospective genotyping and clinical follow-up in RODCM. The main results of this pilot analysis can be summarized as follows: firstly, more than half of RODCM cases has a monogenic or oligogenic genetic background. Secondly, carriers of non-titin disease-related variants are less likely to reach LVRR at 12 months as compared with remaining individuals.

\section{Clinical and genetic screening to detect genetic cause of DCM}

A positive family history of DCM is reported in 10 to $20 \%$ of cases $^{15,20}$. Echocardiographic screening in firstdegree relatives may uncover LV enlargement and / or LV systolic dysfunction in almost one third of the relatives. A quarter of these relatives with abnormal echocardiography later develop symptomatic cardiomyopathy ${ }^{20}$. Most cases of familial DCM have an autosomal dominant mode of inheritance sometimes with incomplete penetrance and 
variable expressivity ${ }^{15}$. This exposes the relatives to risk of major adverse cardiovascular events, which could be prevented. Therefore, recent guidelines recommend obtaining a family history of at least 3 generations and clinical screening in first-degree relatives in all patients with unexplained cardiomyopathy ${ }^{15}$. Genetic testing in unexplained DCM is a recommendation level A. Our data suggest genetic determination in a substantial proportion of unselected patients with recent-onset dilated cardiomyopathy and thus support the recommendation of genetic testing.

\section{Genetic architecture of RODCM and its reversibility}

Whole-exome genetic screening in our RODCM cohort revealed disease-related variants in 28 different genes with predominance of truncating variants of $T T N$ (12\%). Since our study group contained mainly sporadic cases of DCM, this is in agreement with previous studies showing that truncating variants of TTN contribute to $12-18 \%$ of sporadic cases and 20-25\% of familial cases of DCM (ref. ${ }^{14,19-20}$ ). Truncating variants in cardiac long isoform of $T T N$ can be detected also in $0.5 \%$ of healthy general population and were previously associated with larger left ventricular volumes in their carriers. Animal studies suggested that these $T T N$ variants lead to increased fragility to metabolic insults or volume overload, which may trigger evolution of DCM (ref. ${ }^{31}$ ). This was confirmed in 2 landmark clinical trials showing increased prevalence of truncating TTN variants in alcoholic and peripartum cardiomyopathy reaching values of $9.9 \%$ and $15 \%$, respectively $^{32,33}$. Both alcoholic and peripartum cardiomyopathy are known as relatively reversible diseases. There are few retrospective studies showing a marked reversibility also in dilated cardiomyopathy due to truncating variants of TTN suggesting the role of other contributing factors in this disease as pressure or volume overload or a toxic insult ${ }^{34,35}$.

Non-titin gene variants involved in the pathophysiology of our RODCM cases were extremely heterogeneous with a predominance of sarcomeric genes. The most common were variants of cardiac myosin binding protein $\mathrm{C} 3$ (MYBPC3) and cardiac beta myosin heavy chain (MYH7) accounting for 4 to $6 \%$ of cases. Interestingly, in this reallife cohort of RODCM patients, we found very few variants of genes associated with a poor outcome of dilated cardiomyopathy like $L M N A, D E S, R B M 20$ and FLNC (ref. ${ }^{19}$ ). There is limited evidence regarding the occurrence of LVRR in non-titin mutation carriers with the exception of laminopathies. The available studies in laminopathies have documented the absence of LVRR and poor prognosis $^{34-36}$. Further studies are needed to assess LVRR and prognosis in non-titin mutation carriers with RODCM.

\section{Study limitations}

We performed this pilot study to develop the methodology of genomic and clinical data analysis in individuals with RODCM. The relatively small sample size limits the applicability of the data and precludes conclusions regarding association between genotype and hard clinical outcomes as mortality and morbidity. One of the general limitations of WES compared to predefined gene panels is the difficulty in interpretation of the results. In clinical settings it is advisable to assess WES only if $\mathrm{f}$ the family size is large enough for segregation analysis ${ }^{23}$. We are aware of incomplete clinical and genetic screening in affected families, which could improve interpretation of pathogenicity in detected variants. The main reason was the relatively poor participation of families in the genetic and clinical screening, presumably due to often long travel distances. However, this screening is still ongoing and will hopefully bring in more relatives in the near future.

\section{CONCLUSION}

This pilot study is a first whole-exome sequencing study describing the genetic architecture of recent-onset dilated cardiomyopathy in the Moravian region. We discovered that a substantial proportion of RODCM cases have a monogenic or oligogenic genetic background. We found that carriers of non-titin disease-related variants were less likely to reach left ventricular reverse remodelling at 12 months compared to the remaining individuals. This could be seen as a negative prognostic marker of disease development. Further studies are needed to assess the relationship between genotype and hard clinical outcomes in RODCM. We believe that genetic testing could contribute to prognostic evaluation and even individualized treatment of RODCM in the near future.

\section{ABBREVIATIONS}

ECG, Electrocardiography; CHF, Heart failure; DCM, Dilated cardiomyopathy; ICD, Implantable cardioverter-defibrillator; LV, Left ventricular; LVEDD, Left ventricular end-diastolic diameter; LVEF, Left ventricular ejection fraction; LVRR, Left ventricular reverse remodelling; NGS, Next-generation sequencing; NYHA, New York Heart Association; RODCM, Recent onset dilated cardiomyopathy; SD, Standard deviation; WES, Whole exome sequencing.

Acknowledgements: This study was supported by the research grant of the Ministry of Health, Czech Republic: MZ 15-27682A. All rights reserved.

Author contributions: AC: data collection, data interpretation, manuscript writing and literature search; MK: study design, study organization, statistical analysis, data interpretation, drafting of the manuscript; LP: next-generation genetic testing, data interpretation, drafting of the manuscript; JB: data collection and interpretation, drafting of the manuscript; VS: analysis of genomic data, data interpretation; SK: analysis of genomic data, data interpretation, drafting of the manuscript; IG: genetic counselling, data collection, gene-specific genetic testing; JK: data collection, study organization.

Conflict of interest statement: None declared. 


\section{REFERENCES}

1. Yancy CW, Jessup M, Bozkurt B, Butler J, Casey DE, Drazner MH, Fonarow GC, Geraci SA, Horwich T, Januzzi JL, Johnson MR, Kasper EK, Levy WC, Masoudi FA, McBride PE, McMurray JJV, Mitchell JE, Peterson PN, Riegel B, Sam F, Stevenson LW, Tang WHW, Tsai EJ, Wilkoff BL. 2013 ACCF/AHA guideline for the management of heart failure: executive summary: a report of the American College of Cardiology Foundation/American Heart Association Task Force on practice guidelines. Circulation 2013;128(16):1810-52.

2. Elliott $P$, Andersson $B$, Arbustini E, Bilinska Z, Cecchi F, Charron $P$ Dubourg O, Kühl U, Maisch B, McKenna WJ, Monserrat L, Pankuweit S, Rapezzi C, Seferovic P, Tavazzi L, Keren A. Classification of the cardiomyopathies: a position statement from the European Society Of Cardiology Working Group on Myocardial and Pericardial Diseases. Eur Heart J 2008;29(2):270-6.

3. Pinto YM, Elliott PM, Arbustini E, Adler $Y$, Anastasakis A, Böhm M, Duboc D, Gimeno J, de Groote P, Imazio M, Heymans S, Klingel K, Komajda M, Limongelli G, Linhart A, Mogensen J, Moon J, Pieper PG, Seferovic PM, Schueler S, Zamorano JL, Caforio ALP, Charron P. Proposal for a revised definition of dilated cardiomyopathy, hypokinetic non-dilated cardiomyopathy, and its implications for clinical practice: a position statement of the ESC working group on myocardial and pericardial diseases. Eur Heart J 2016;37(23):1850-8.

4. Rapezzi C, Arbustini E, Caforio ALP, Charron P, Gimeno-Blanes J, Heliö T, Linhart A, Mogensen J, Pinto Y, Ristic A, Seggewiss H, Sinagra G, Tavazzi L, Elliott PM. Diagnostic work-up in cardiomyopathies: bridging the gap between clinical phenotypes and final diagnosis. A position statement from the ESC Working Group on Myocardial and Pericardial Diseases. Eur Heart J 2013;34(19):1448-58.

5. Šramko $M$, Kubánek $M$, Tintěra J, Kautznerová $D$, Weichet J Malušková J, Franeková J, Kautzner J. Utility of combination of cardiac magnetic resonance imaging and high-sensitivity cardiac troponin T assay in diagnosis of inflammatory cardiomyopathy. Am J Cardiol 2013;111(2):258-64.

6. Bozkurt B, Colvin M, Cook J, Cooper LT, Deswal A, Fonarow GC Francis GS, Lenihan D, Lewis EF, McNamara DM, Pahl E, Vasan RS Ramasubbu K, Rasmusson K, Towbin JA, Yancy C, American Heart Association Committee on Heart Failure and Transplantation of the Council on Clinical Cardiology; Council on Cardiovascular Disease in the Young; Council on Cardiovascular and Stroke Nursing; Council on Epidemiology and Prevention; and Council on Quality of Care and Outcomes Research. Current Diagnostic and Treatment Strategies for Specific Dilated Cardiomyopathies: A Scientific Statement From the American Heart Association. Circulation 2016;134(23):e579-646.

7. Givertz MM, Mann DL. Epidemiology and natural history of recovery of left ventricular function in recent onset dilated cardiomyopathies. Curr Heart Fail Rep 2013;10(4):321-30.

8. Merlo M, Pyxaras SA, Pinamonti B, Barbati G, Di Lenarda A, Sinagra G. Prevalence and prognostic significance of left ventricular reverse remodeling in dilated cardiomyopathy receiving tailored medical treatment. J Am Coll Cardiol 2011;57(13):1468-76.

9. Kubanek M, Sramko M, Maluskova J, Kautznerova D, Weichet J, Lupinek P, Vrbska J, Malek I, Kautzner J. Novel predictors of left ventricular reverse remodeling in individuals with recent-onset dilated cardiomyopathy. J Am Coll Cardiol 2013;61(1):54-63.

10. Krejci J, Hude P, Ozabalova E, Mlejnek D, Zampachova V, Svobodova I, Stepanova R, Spinarova L. Improvement of left ventricular sys tolic function in inflammatory cardiomyopathy: What plays a role? Biomed Pap Med Fac Univ Palacky Olomouc Czechoslov 2016;160(4):524-32.

11. Merlo M, Pyxaras SA, Pinamonti B, Barbati G, Di Lenarda A, Sinagra $G$. Prevalence and prognostic significance of left ventricular reverse remodeling in dilated cardiomyopathy receiving tailored medical treatment. J Am Coll Cardiol 2011;57(13):1468-76.

12. Hershberger RE, Hedges DJ, Morales A. Dilated cardiomyopathy: the complexity of a diverse genetic architecture. Nat Rev Cardiol 2013;10(9):531-47.

13. Hershberger RE, Norton N, Morales A, Li D, Siegfried JD, GonzalezQuintana J. Coding sequence rare variants identified in MYBPC3, MYH6, TPM1, TNNC1, and TNNI3 from 312 patients with familial or idiopathic dilated cardiomyopathy. Circ Cardiovasc Genet 2010;3(2):155-61

14. Herman DS, Lam L, Taylor MRG, Wang L, Teekakirikul P, Christodoulou
D, Conner L, DePalma SR, McDonough B, Sparks E, Teodorescu DL, Cirino AL, Banner NR, Pennell DJ, Graw S, Merlo M, Di Lenarda A, Sinagra G, Bos JM, Ackerman MJ, Mitchell RN, Murry CE, Lakdawala NK, Ho CY, Barton PJR, Cook SA, Mestroni L, Seidman JG, Seidman CE. Truncations of titin causing dilated cardiomyopathy. N Engl J Med 2012;366(7):619-28.

15. Hershberger RE, Givertz MM, Ho CY, Judge DP, Kantor PF, McBride KL, Morales A, Taylor MRG, Vatta M, Ware SM. Genetic Evaluation of Cardiomyopathy-A Heart Failure Society of America Practice Guideline. J Card Fail 2018;24(5):281-302.

16. Lopes LR, Elliott PM. Genetics of heart failure. Biochim Biophys Acta 2013;1832(12):2451-61.

17. Taylor MRG, Fain PR, Sinagra G, Robinson ML, Robertson AD, Carniel E, Di Lenarda A, Bohlmeyer TJ, Ferguson DA, Brodsky GL, Boucek MM Lascor J, Moss AC, Li WLP, Stetler GL, Muntoni F, Bristow MR, Mestroni L, Familial Dilated Cardiomyopathy Registry Research Group. Natural history of dilated cardiomyopathy due to lamin A/C gene mutations. J Am Coll Cardiol 2003;41(5):771-80.

18. van Rijsingen IAW, van der Zwaag PA, Groeneweg JA, Nannenberg EA, Jongbloed JDH, Zwinderman AH, Pinto YM, Dit Deprez RHL, Post JG, Tan HL, de Boer RA, Hauer RNW, Christiaans I, van den Berg MP, van Tintelen JP, Wilde AAM. Outcome in phospholamban R14del carriers: results of a large multicentre cohort study. Circ Cardiovasc Genet 2014;7(4):455-65.

19. Kayvanpour E, Sedaghat-Hamedani F, Amr A, Lai A, Haas J, Holzer DB, Frese KS, Keller A, Jensen K, Katus HA, Meder B. Genotypephenotype associations in dilated cardiomyopathy: meta-analysis on more than 8000 individuals. Clin Res Cardiol Off J Ger Card Soc 2017;106(2):127-39.

20. Baig MK, Goldman JH, Caforio AL, Coonar AS, Keeling PJ, McKenna WJ. Familial dilated cardiomyopathy: cardiac abnormalities are common in asymptomatic relatives and may represent early disease. J Am Coll Cardiol 1998;31(1):195-201.

21. Lang RM, Bierig M, Devereux RB, Flachskampf FA, Foster E, Pellikka PA, Picard MH, Roman MJ, Seward J, Shanewise JS, Solomon SD, Spencer KT, Sutton MSJ, Stewart WJ, Chamber Quantification Writing Group, American Society of Echocardiography's Guidelines and Standards Committee, European Association of Echocardiography. Recommendations for chamber quantification: a report from the American Society of Echocardiography's Guidelines and Standards Committee and the Chamber Quantification Writing Group, developed in conjunction with the European Association of Echocardiography, a branch of the European Society of Cardiology. J Am Soc Echocardiogr Off Publ Am Soc Echocardiogr 2005;18(12):1440-63.

22. Quiñones MA, Otto CM, Stoddard M, Waggoner A, Zoghbi WA, Doppler Quantification Task Force of the Nomenclature and Standards Committee of the American Society of Echocardiography. Recommendations for quantification of Doppler echocardiography: a report from the Doppler Quantification Task Force of the Nomenclature and Standards Committee of the American Society of Echocardiography. J Am Soc Echocardiogr Off Publ Am Soc Echocardiogr 2002;15(2):167-84.

23. Pinto YM, Elliott PM, Arbustini E, Adler Y, Anastasakis A, Böhm M, Duboc D, Gimeno J, de Groote P, Imazio M, Heymans S, Klingel K, Komajda M, Limongelli G, Linhart A, Mogensen J, Moon J, Pieper PG, Seferovic PM, Schueler S, Zamorano JL, Caforio ALP, Charron P. Proposal for a revised definition of dilated cardiomyopathy, hypokinetic non-dilated cardiomyopathy, and its implications for clinical practice: a position statement of the ESC working group on myocardial and pericardial diseases. Eur Heart J 2016;37(23):1850-8.

24. McKenna A, Hanna M, Banks E, Sivachenko A, Cibulskis K, Kernytsky A, Garimella K, Altshuler D, Gabriel S, Daly M, DePristo MA. The Genome Analysis Toolkit: a MapReduce framework for analyzing next-generation DNA sequencing data. Genome Res 2010;20(9):1297-303.

25. Cingolani P, Platts A, Wang LL, Coon M, Nguyen T, Wang L, Land SJ, Lu $X$, Ruden DM. A program for annotating and predicting the effects of single nucleotide polymorphisms, SnpEff: SNPs in the genome of Drosophila melanogaster strain w1118; iso-2; iso-3. Fly (Austin) 2012;6(2):80-92.

26. Paila U, Chapman BA, Kirchner R, Quinlan AR. GEMINI: integrative exploration of genetic variation and genome annotations. PLoS Comput Biol 2013;9(7):e1003153. 
27. Thorvaldsdóttir H, Robinson JT, Mesirov JP. Integrative Genomics Viewer (IGV): high-performance genomics data visualization and exploration. Brief Bioinform 2013;14(2):178-92.

28. Burke MA, Cook SA, Seidman JG, Seidman CE. Clinical and Mechanistic Insights Into the Genetics of Cardiomyopathy. J Am Coll Cardiol 2016;68(25):2871-86

29. Richards S, Aziz N, Bale S, Bick D, Das S, Gastier-Foster J, Grody WW, Hegde M, Lyon E, Spector E, Voelkerding K, Rehm HL. Standards and Guidelines for the Interpretation of Sequence Variants: A Joint Consensus Recommendation of the American College of Medical Genetics and Genomics and the Association for Molecular Pathology. Genet Med Off J Am Coll Med Genet [Internet] 2015 May [cited $2018 \mathrm{Jul} 30] ; 17(5): 405-24$. Available from: https://www.ncbi. nlm.nih.gov/pmc/articles/PMC4544753/

30. Schwarz JM, Cooper DN, Schuelke M, Seelow D. MutationTaster2 mutation prediction for the deep-sequencing age. Nat Methods 2014;11(4):361-2.

31. Akinrinade $O$, Ollila L, Vattulainen $S$, Tallila J, Gentile M, Salmenperä $P$, Koillinen $H$, Kaartinen M, Nieminen MS, Myllykangas S, Alastalo T-P, Koskenvuo JW, Heliö T. Genetics and genotype-phenotype correlations in Finnish patients with dilated cardiomyopathy. Eur Heart J 2015;36(34):2327-37.

32. Schafer S, de Marvao A, Adami E, Fiedler LR, Ng B, Khin E, Rackham OJL, van Heesch S, Pua CJ, Kui M, Walsh R, Tayal U, Prasad SK, Dawes TJW, Ko NSJ, Sim D, Chan LLH, Chin CWL, Mazzarotto F, Barton PJ, Kreuchwig F, de Kleijn DPV, Totman T, Biffi C, Tee N, Rueckert D, Schneider V, Faber A, Regitz-Zagrosek V, Seidman JG, Seidman CE, Linke WA, Kovalik J-P, O'Regan D, Ware JS, Hubner N, Cook SA. Titintruncating variants affect heart function in disease cohorts and the general population. Nat Genet 2017;49(1):46-53.
33. Ware JS, Amor-Salamanca A, Tayal U, Govind R, Serrano I, SalazarMendiguchía J, García-Pinilla JM, Pascual-Figal DA, Nuñez J, GuzzoMerello G, Gonzalez-Vioque E, Bardaji A, Manito N, López-Garrido MA, Padron-Barthe L, Edwards E, Whiffin N, Walsh R, Buchan RJ, Midwinter W, Wilk A, Prasad S, Pantazis A, Baski J, O'Regan DP, Alonso-Pulpon L, Cook SA, Lara-Pezzi E, Barton PJ, Garcia-Pavia P. Genetic Etiology for Alcohol-Induced Cardiac Toxicity. J Am Coll Cardiol 2018;71(20):2293-302.

34. Ware JS, Li J, Mazaika E, Yasso CM, DeSouza T, Cappola TP, Tsai EJ, Hilfiker-Kleiner D, Kamiya CA, Mazzarotto F, Cook SA, Halder I, Prasad SK, Pisarcik J, Hanley-Yanez K, Alharethi R, Damp J, Hsich E, Elkayam U, Sheppard R, Kealey A, Alexis J, Ramani G, Safirstein J, Boehmer J, Pauly DF, Wittstein IS, Thohan V, Zucker MJ, Liu P, Gorcsan J, McNamara DM, Seidman CE, Seidman JG, Arany Z, IMAC-2 and IPAC Investigators. Shared Genetic Predisposition in Peripartum and Dilated Cardiomyopathies. N Engl J Med 20161;374(3):233-41.

35. Jansweijer JA, Nieuwhof K, Russo F, Hoorntje ET, Jongbloed JDH, Lekanne Deprez RH, Postma AV, Bronk M, van Rijsingen IAW, de Haij $S$, Biagini $E$, van Haelst $P L$, van Wijngaarden J, van den Berg MP, Wilde AAM, Mannens MMAM, de Boer RA, van Spaendonck-Zwarts KY, van Tintelen JP, Pinto YM. Truncating titin mutations are associated with a mild and treatable form of dilated cardiomyopathy. Eur J Heart Fail 2017;19(4):512-21.

36. Tobita T, Nomura S, Fujita T, Morita H, Asano Y, Onoue $K$, Ito M, Imai Y, Suzuki A, KoT, Satoh M, Fujita K, Naito AT, Furutani Y, Toko H, Harada M, Amiya E, Hatano M, Takimoto E, Shiga T, Nakanishi T, Sakata Y, Ono M, Saito Y, Takashima S, Hagiwara N, Aburatani H, Komuro I. Genetic basis of cardiomyopathy and the genotypes involved in prognosis and left ventricular reverse remodeling. Sci Rep 2018;8(1):1998. 